\title{
La graduación ad hoc de las infracciones. Motivos para la discusión
}

\section{Ad hoc graduation of offences. reasons for discussion}

\author{
Miguel Casino Rubio \\ Universidad Carlos III de Madrid (España) \\ ORCID: https://orcid.org/0000-0001-7071-4090 \\ miguel.casino@uc3m.es
}

\begin{abstract}
NOTA BIOGRÁFICA
Profesor Titular de Derecho Administrativo. Universidad Carlos III de Madrid. Ex Letrado del Tribunal Constitucional. Entre sus líneas de investigaciones figura precisamente el Derecho administrativos sancionador, al que ha dedicado varios trabajos. Últimamente, "La ejecutividad de las sanciones administrativas y el pistolero anda suelto", Anuario de Derecho Administrativo Sancionador, Civitas-Thomson Aranzadi, 2021; y El concepto constitucional de sanción administrativa, CEPC, Madrid, 2. ${ }^{a}$ ed., 2021 (en prensa).
\end{abstract}

\section{RESUMEN}

Habitualmente las leyes administrativas cuando tipifican infracciones se encargan también de clasificarlas en función de su gravedad. Pero no siempre es así. No son pocas, de hecho, las leyes que confían esa operación de clasificación al desarrollo reglamentario o, como es más común que suceda, a la propia Administración sancionadora. Este artículo analiza esta forma de tipificación de las infracciones y alerta sobre las principales debilidades de la tesis hoy dominante que niega su constitucionalidad.

\section{PALABRAS CLAVE}

Graduación ad hoc de las infracciones; mandato de taxatividad; margen de apreciación; consecuencias sancionadoras.

\section{ABSTRACT}

Administrative laws when describing violations are usually also handled by classifying them according to their severity. But it's not always like that. There are few, in fact, laws entrusting such a classification operation to regulatory development or, more commonly, to the sanctioning ordinating administration itself. This article discusses this form of criminality of infringements and warns about the main weaknesses of the now dominant thesis that denies its constitutionality.

\section{KEYWORDS}

Ad hoc classification of administrative offences; mandate of taxativity; discretion; sanctioning consequences.

\section{SUMARIO}

I. PLANTEAMIENTO. II. LA OPINIÓN DE LA JURISPRUDENCIA. EN ESPECIAL, LA DOCTRINA DEL TRIBUNAL CONSTITUCIONAL: 1. LA CLASIFICACIÓN POR VÍA REGLAMENTARIA. 2. LA GRADUACIÓN POR LA PROPIA ADMINISTRACIÓN SANCIONADORA. III. OBSERVACIONES CRÍTICAS A LA 
PROHIBICIÓN DE LA CLASIFICACIÓN AD HOC DE LAS INFRACCIONES: 1. UNA DECLARACIÓN CONSTITUCIONAL SUMARIA Y SIN APENAS EXPLICACIÓN. 2. LA DISTINTA VARA DE MEDIR LA GRADUACIÓN DE LAS INFRACCIONES Y DE LAS SANCIONES. 3. NO HAY RAZONES PARA LA DISTINCIÓN Y LA ESENCIALIDAD DE LA SANCIÓN. 4. EL TAMAÑO DE LA HORQUILLA SANCIONADORA Y SUS CONSECUENCIAS. 5. LOS CRITERIOS LEGALES, EL MARGEN ADMINISTRATIVO DE APRECIACIÓN Y LA INSEGURIDAD. 6. UNA VUELTA FINAL POR LAS LEYES SANCIONADORAS Y UNA PREGUNTA SOBRE SU FUTURO. REFERENCIAS BIBLIOGRÁFICAS.

\section{PLANTEAMIENTO}

Las leyes administrativas, cuando tipifican infracciones, lo hacen comúnmente clasificándolas en alguna de las categorías de leves, graves o muy graves que hoy ordena el art. 27.1 de la Ley 40/2105, de 1 de octubre, de Régimen Jurídico del Sector Público (LRJSP) ${ }^{1}$. Pero no siempre es así. De hecho, no faltan los ejemplos de leyes que, después de tipificar las correspondientes infracciones, no las clasifican sin embargo en ninguna de esas categorías, remitiendo esa operación a un momento posterior. Esta remisión se expresa en esas mismas leyes siguiendo fórmulas distintas.

Hay, en primer lugar, leyes que confían esa operación de clasificación de las infracciones al desarrollo reglamentario. En lo que he podido comprobar, es el caso singularmente del Texto Refundido de la Ley de Aguas, aprobado por Real Decreto Legislativo 1/2001, de 20 de julio (en adelante TRLA). La ley, después de tipificar en su art. 116.3 las conductas infractoras, establece en el siguiente art. 117.1 que:

«Las citadas infracciones se calificarán reglamentariamente de leves, menos graves, graves, o muy graves, atendiendo a su repercusión en el orden y aprovechamiento del dominio público hidráulico, a su trascendencia por lo que respecta a la seguridad de las personas y bienes y a las circunstancias del responsable, su grado de malicia, participación y beneficio obtenido, así como al deterioro producido en la calidad del recurso [...]».

La misma fórmula, redactada en forma prácticamente idéntica, utilizaba el art. 70.1 de la Ley autonómica 10/1987, de 5 de mayo, de Aguas de Canarias, y renueva hoy el art. 125.1 de la vigente Ley canaria 12/1996, de 26 de julio, de Aguas, al establecer que:

«El gobierno procederá a calificar las infracciones en leves, menos graves, graves, o muy graves, atendiendo a su repercusión en el régimen y aprovechamiento del dominio público hidráulico, a su trascendencia respecto a la seguridad de las personas y bienes y a las circunstancias, grado de malicia, participación y beneficio obtenido por el responsable, así como al deterioro producido en la calidad del recurso».

Y las hay también, en segundo lugar y en mayor número, que descargan esa operación de clasificación simplemente en un momento posterior y, en particular, en la decisión del propio órgano sancionador con ocasión de cada procedimiento sancionador.

Según mis cuentas, la Ley, ya derogada, 8/1980, de 10 de marzo, del Estatuto de los Trabajadores (ET 1980), fue una de las primeras en hacerlo, aunque lo hiciera entonces refiriéndose en rigor a las sanciones. Su artículo 57, sobre infracciones laborales de los empresarios, establecía en su primer apartado que «son infracciones laborales de los empresarios las acciones $u$ omisiones contrarias a las disposiciones legales en materia de trabajo», para precisar a renglón seguido en el siguiente apartado 2 que:

«Las sanciones se graduarán en atención a la gravedad de la infracción, malicia o falsedad del empresario, número de trabajadores afectados, cifra de negocios de la empresa y reincidencia».

\footnotetext{
1 Aunque como se ha notado en el texto, la indicada es ciertamente la regla que sienta hoy la LRJSP y es también la que mayoritariamente sigue el legislador sectorial, conviene advertir que la clasificación de las infracciones según su gravedad en alguna de las citadas categorías no es ninguna exigencia constitucional y que, por tanto, son perfectamente legítimas las tipificaciones que no se ajustan a la citada clasificación tripartita, bien porque siguen otra clasificación tripartita distinta (por ejemplo, art. 48 de la Ley de Caza de 1970), bien porque establecen una cuatripartita (leves, menos graves, graves y muy graves, según prueban varios de los ejemplos que luego se anotarán en el texto) o, incluso, porque no fijan ninguna (como es el caso del art. 76 de la Ley 16/1985, de 25 de junio, de Patrimonio Histórico Español). Esta última es, por cierto, la solución que siguen otros ordenamientos comparados y señaladamente el alemán según testimonia Valencia (2000, p. 134).
} 
Años después, la Ley, hoy también hoy derogada, 4/1989, de 27 de marzo, de conservación de los espacios naturales y de la flora y fauna silvestres (LCEN), y cuyo interés notaremos más adelante, adoptó parecido planteamiento. La Ley tipificaba en el art. 38 una larga lista de infracciones para añadir luego en el siguiente art. 39.1 que:

«Las citadas infracciones serán calificadas de leves, menos graves, graves y muy graves, atendiendo a su repercusión, a su trascendencia por lo que respecta a la seguridad de las personas y bienes y a las circunstancias del responsable, su grado de malicia, participación y beneficio obtenido, así como la irreversibilidad del daño o deterioro producido en la calidad del recurso o del bien protegido».

El mismo o parecido modelo siguen hoy otras leyes vigentes, autonómicas o del Estado. Entre las primeras, es el caso, por ejemplo, de la Ley 3/1992, de 21 de mayo, por la que se establecen medidas excepcionales para la regulación del abastecimiento de agua en la Comunidad de Madrid. Su art. 5, después también de declarar que «se considera infracción administrativa cualquier acción u omisión que comporte vulneración de lo dispuesto en la presente Ley y en las disposiciones que la desarrollen», precisa que:

«Las infracciones se calificarán como leves, graves y muy graves, atendiendo a la naturaleza de la prohibición infringida, a su repercusión, al perjuicio causado, a las circunstancias del responsable, al beneficio obtenido y a la reincidencia. [...]».

Y del lado estatal, y más modernamente, ese es también el caso de la Ley 39/2006, de 14 de diciembre, de promoción de la autonomía personal y atención a las personas en situación de dependencia. En términos muy parecidos, la ley tipifica en su art. 43 una larga lista de infracciones para añadir asimismo en el siguiente art. 44.1 que:

«Las infracciones se clasificarán en leves, graves y muy graves, de acuerdo con criterios de riesgo para la salud, gravedad de la alteración social producida por los hechos, cuantía del beneficio obtenido, intencionalidad, número de afectados y reincidencia».

Aunque seguramente hay muchos más ejemplos salpicados por nuestro ordenamiento, es de todas formas en materia de defensa y protección de los consumidores y usuarios en donde esta forma de tipificar ha hecho verdadera fortuna.

A la cabeza de este grupo de leyes se colocó en su momento la Ley 26/1984, de 19 de julio, general para la defensa de los consumidores y usuarios. Con arreglo al modelo que ya conocemos, después de tipificar las infracciones, la ley advertía efectivamente que:

«Las infracciones se calificarán como leves, graves y muy graves, atendiendo a los criterios de riesgo para la salud, posición en el mercado del infractor, cuantía de beneficio obtenido, grado de intencionalidad, gravedad de la alteración social producida, generalización de la infracción y la reincidencia» (art. 35).

El vigente el Texto Refundido de la Ley general para la defensa de los consumidores y usuarios (LCU), aprobado por Real Decreto Legislativo 1/2007, de 16 de noviembre, mantiene el mismo esquema, de modo que tipifica también una larga lista de infracciones para precisar a renglón seguido que.

«[esas] infracciones podrán calificarse por las Administraciones públicas competentes como leves, graves y muy graves, atendiendo a los criterios de riesgo para la salud, posición en el mercado del infractor, cuantía del beneficio obtenido, grado de intencionalidad, gravedad de la alteración social producida, generalización de la infracción y reincidencia» (art. 50.1).

Entre medias de estas dos leyes del Estado hay un buen número de leyes autonómicas en la materia que siguen la misma fórmula para clasificar las infracciones.

De esa época, interesa anotar en este momento la Ley, ya derogada, del Parlamento de Cataluña 3/1993, de 5 de marzo, del estatuto del consumidor. Su art. 30, cuyo interés notaremos más adelante, establecía en términos del todo semejantes a la norma estatal de 1984 que las infracciones que la ley previamente tipificaba:

«[s]e calificarán como leves, graves o muy graves en función del riesgo que supongan para la salud o seguridad de los consumidores, con especial atención a las de los que están espe- 
cialmente protegidos por la presente Ley, en función de la cuantía del beneficio obtenido como consecuencia directa o indirecta de la infracción, en función de la situación de predominio del infractor en algún sector del mercado y en función de su reincidencia».

La misma fórmula, matices aparte, podía leerse asimismo en las leyes, también ya derogadas, 8/1997, de 30 de octubre, del estatuto del consumidor y usuario de la Comunidad Autónoma de Aragón (art. 43.2); y 11/1998, de 5 de diciembre, para la defensa de los consumidores y usuarios de Castilla y León (art. 25).

Y luce igualmente en las más modernas y vigentes leyes 11/2002, de 2 de diciembre, de los consumidores y usuarios del Principado de Asturias (art. 39); 6/2003, de 22 de diciembre, de estatuto de las personas consumidoras y usuarias del País Vasco (art. 52); 13/2003, de 17 de diciembre, de defensa y protección de los consumidores y usuarios de Andalucía (art. 72); o, en fin, la Ley Foral 7/2006, de 20 de junio, de defensa de los consumidores y usuarios de Navarra (art. 40), y que luego repasaremos.

Aunque la lista podría alargarse, me parece que los ejemplos anteriores son suficientes para probar que efectivamente esa forma de tipificar las infracciones, que remite a un momento posterior la clasificación de las infracciones en leves, graves o muy graves, no es ni mucho menos infrecuente, ni tampoco tan antigua ni en desuso. De todos modos, que esa fórmula no sea excepcional, no significa naturalmente que no sea controvertida ni que esté libre de reproches, según lo confirma el repaso a la jurisprudencia, con la doctrina del Tribunal Constitucional a la cabeza².

\section{LA OPINIÓN DE LA JURISPRUDENCIA. EN ESPECIAL, LA DOCTRINA DEL TRIBUNAL CONSTITUCIONAL}

Según he adelantado, esa forma de tipificación de las infracciones, en las dos modalidades que hemos repasado, ha sido efectivamente cuestionada en los tribunales y ante el Tribunal Constitucional con el argumento de que la correspondiente fórmula legal infringe el principio de legalidad sancionadora, en su vertiente material de taxatividad o de lex certa que garantiza el art. 25.1 CE.

\section{La clasificación por vía reglamentaria}

Sobre la primera modalidad, la que permite o remite de modo expreso al desarrollo reglamentario la clasificación de las infracciones según su gravedad, el Tribunal Supremo se ha pronunciado en unas pocas ocasiones.

Lo ha hecho, en primer lugar, aunque con algunos matices ${ }^{3}$, a propósito del art. 57.2 ET 1980, que antes se ha recordado, para declarar que esa forma de tipificación.

«otorga a la Administración laboral un arbitrio desmedido en la elección de la respuesta punitiva, que sin duda no se adecua al rigor de la reserva de ley y del principio "nullum crimen, mulla pena sine lege", [puesto que] los criterios de graduación del art. 57.2 no suponen sino pautas genéricas, insuficientes de por sí para objetivar apriorísticamente la correspondencia precisa entre la sanción y la infracción» (SSTS de 20 de diciembre de 1989 y de 5 de marzo de 1990).

2 Curiosamente, no puede decirse lo mismo de la doctrina científica especializada, que apenas ha reparado en este asunto. A salvo de los apuntes de Valencia (2018, p. 934) que se hacen eco de la doctrina constitucional al respecto; de la muy notable excepción del estudio de Rebollo y Cano (2021), cuyo texto, pendiente de publicación, he podido consultar por amabilidad de sus autores; y de la opinión de Izquierdo (2001, pp. 222 y ss.) contraria asimismo a que la ley pueda remitir la clasificación de las infracciones por su gravedad al reglamento de desarrollo, debo confesar que, rebuscando en los trabajos de los principales autores del derecho administrativo sancionador, no he podido encontrar muchas otras referencias. Lo más que he podido ver son puntuales anotaciones de la doctrina constitucional y unas pocas observaciones sobre las técnicas más usuales de las que se sirve el legislador para cumplir con el mandato de tipificación, en su vertiente material de taxatividad (lex certa), y sobre el apoderamiento que esas fórmulas otorgan a la Administración. Cfr., por todos, Gómez y Sanz (2013, pp. 165-166); Casares (2012, pp. 129-131); y Nieto (2012, en especial, pp. 511 y ss.).

3 En una serie, que arranca con la STS de 10 de noviembre de 1986, el Tribunal Supremo censuró el citado RD $2347 / 1985$ y declaró su nulidad por vulnerar el principio de legalidad sancionadora del art. 25.1 CE, en su vertiente de tipicidad. Pero lo hizo en rigor, no por el motivo que particularmente nos interesa en el texto, sino porque el art. 57 ET 1980 («son infracciones laborales de los empresarios las acciones u omisiones contrarias a las disposiciones legales en materia de trabajo») tipificaba las infracciones con arreglo a una fórmula demasiado vaga y abierta, que no permitía conocer sus elementos esenciales y concedía, en consecuencia, un excesivo arbitrio a la norma de desarrollo, que era de este modo la que realmente contenía la descripción de las conductas infractoras, con independencia de su gravedad. 
Pero sobre todo lo ha hecho de modo expreso a propósito del art. 7 del Real Decreto 1095/1989, de 8 de septiembre, que, en desarrollo del art. 39 LCEN que ya conocemos, clasificaba determinadas infracciones como graves, menos graves y leves.

Al respecto, la STS de 9 de noviembre 1993, a la que luego siguieron ad pedem litterae las SSTS de 14 de marzo de 1996 y de 18 de noviembre de 2002, nota que la LCEN se limita, matices aparte, a señalar los criterios a observar para la clasificación de las infracciones según su gravedad y, en consecuencia, declara que la calificación como grave de la infracción entonces considerada y la correspondiente sanción.

«no se han hecho por la Ley, sino por el Reglamento, en clara vulneración del art. 25.1 de la Constitución, con arreglo al cuál [...] no sólo debe figurar en la Ley la definición de los ilícitos y de las sanciones, sino también el establecimiento de la correspondencia necesaria entre aquéllos y éstas. Por consiguiente, ha de concluirse que la sanción de multa impuesta al hoy apelante no tiene la cobertura legal exigida por el art. 25.1 de la Constitución».

Muy distinta es, sin embargo, la opinión del Tribunal Constitucional que no ha visto en la calificación de la gravedad de las infracciones por vía reglamentaria ninguna vulneración del art. 25.1 CE.

Esta es, en efecto, la conclusión que de modo singular declara el ATC 34/2012, de 14 de febrero, y que pocos meses después confirmó el ATC 111/2012, de 22 de mayo, con motivo precisamente de inadmitir a trámite, por notoriamente infundadas, sendas cuestiones de inconstitucionalidad planteadas contra el art. 117.1 TRLA por posible vulneración del principio de legalidad sancionadora del art. 25.1 CE.

En ambos casos, los respectivos órganos judiciales cuestionaron la constitucionalidad del citado precepto legal razonando que la ley no podía descargar en la potestad reglamentaria la tarea de determinar el carácter leve, grave o muy grave de las infracciones, con solo atenerse a los criterios de graduación que la ley le señalaba.

El Tribunal Constitucional, sin embargo, no compartió este planteamiento. En su lugar, después de recordar que el principio de legalidad sancionadora no excluye la colaboración reglamentaria en la determinación del régimen sancionador y de notar que la Ley de Aguas describía las infracciones y establecía la naturaleza y los límites de las sanciones a imponer en cada caso, así como los criterios para la graduación de las infracciones, declaró que.

«la remisión a la colaboración reglamentaria que realiza el precepto cuestionado [art. 117.1] debe calificarse conforme con las exigencias del art. 25.1 CE, sin que se pueda entender que nos encontremos ante una remisión que haga posible una regulación reglamentaria independiente y no claramente subordinada a la ley».

\section{La graduación por la propia Administración sancionadora}

En la jurisprudencia ordinaria y constitucional hay también un puñado de resoluciones que se pronuncian sobre la segunda modalidad de tipificación de las infracciones, la que descarga o permite su calificación de muy grave, grave o leve por la propia Administración sancionadora con ocasión de cada expediente sancionador, y que aquí particularmente nos va a interesar.

De lado de la jurisprudencia ordinaria, así lo testimonian las SSTS de 19 de abril, 3 de junio y 5 de diciembre de 1991; y de 4 de febrero y 22 de junio de 1992 que censuran otras tantas sanciones impuestas en aplicación del art. 57 ET 1980 que he recordado al principio.

Todas estas sentencias comienzan notando que ese precepto legal solo establece «una definición genérica de infracción laboral del empresario» (las acciones u omisiones contraria a las disposiciones legales en materia de trabajo) y «los criterios generales con arreglo a los cuales han de graduarse las sanciones», pero no determina, en cambio, «qué infracciones son muy graves, graves o leves». Apurando esta comprobación, el Tribunal Supremo declara que,

«por tanto, la autoridad administrativa, en el presente caso, al imponer la sanción impugnada, ha procedido aquí con criterios de decisión singular esto es, haciendo una graduación "ad hoc", y este modo de graduación "ad hoc" no garantiza mínimamente la seguridad jurídica de los administrados, ni cumple las exigencias del art. 25.1 de la Constitución».

Pero es el Tribunal Constitucional el que singularmente se ha pronunciado al respecto. Según mis cuentas, lo ha hecho al menos en otra media docena larga de ocasiones. 
Lo hizo, por primera vez, en la STC 207/1990, de 17 de diciembre. Esta sentencia resuelve el recurso de amparo interpuesto por una empresa contra la sanción administrativa, confirmada luego judicialmente, por la comisión de una infracción del citado art. 57 ET 1980, que la Administración sancionadora decidió calificar entonces de muy grave en grado medio, «en atención a las circunstancias concurrentes en el supuesto enjuiciado y a los debidos criterios de proporcionalidad».

Siguiendo el planteamiento de la demanda, que no discutió la existencia de la infracción, sino únicamente su gradación, el Tribunal declaró que.

«la graduación de la sanción ha de entenderse como una decisión singular, esto es, como una graduación ad hoc que en cada caso concreto lleva a cabo la misma autoridad que impone la sanción, cuya discrecionalidad ni siquiera requiere que se explicite el peso concreto concedido a cada uno de los criterios que la ley ofrece [...]».

Para a renglón seguido añadir que,

«no resultando de norma alguna la distinción entre infracciones muy graves y otras, ni la división de cada una de estas ignotas categorías en distintos grados, es evidente que este modo de graduación ad hoc de la sanción correspondiente a cada concreta infracción no garantiza mínimamente la seguridad jurídica de los administrados [...]. En cuanto que este modo de actuación administrativa es el que se sigue necesariamente de la norma legal, interpretada del modo en que lo ha sido, es patente que dicha norma no cumple con las exigencias materiales que impone el art. 25.1 de nuestra Constitución».

El Tribunal Constitucional no volvería sobre este asunto hasta bastantes años después. Concretamente hasta la STC 100/2003, de 2 de julio, con ocasión entonces de resolver un recurso de amparo en el que se ventilaba la constitucionalidad de la sanción impuesta por la comisión de una infracción del art. 38.13 LCNE y que la Administración decidió calificar de muy grave con arreglo a lo dispuesto en el siguiente art. 39.1, que ya conocemos.

En esa ocasión, el Tribunal declaró igualmente que esa graduación de la gravedad de la infracción por la propia Administración sancionadora vulneró el art. 25.1 CE. Literalmente advirtió que.

«la graduación de las sanciones o calificación ad hoc de las infracciones no resulta acorde con el principio de taxatividad en cuanto que no garantiza mínimamente la seguridad jurídica de los ciudadanos, quienes ignoran las consecuencias que han de seguirse de la realización de una conducta genéricamente tipificada como infracción administrativa» (FJ 6) ${ }^{4}$.

A esta sentencia constitucional le siguieron a los pocos años otras cuatro, dictadas con ocasión de otros tantos recursos de amparo y a propósito igualmente del mismo art. 39.1 LCNE.

Las SSTC 210/2005, de 18 de julio; 98/2006, de 27 de marzo; 187/2006, de 19 de junio; y 252/2006, de 25 de julio, siguen ad pedem litterae la misma declaración constitucional que acaba de recordarse y, en consecuencia, confirman que esa forma de tipificación de las infracciones, que remite (o consiente) su calificación a un momento posterior, sin el que no es posible la aplicación directa e inmediata de la ley, es contraria al art. 25.1 CE. En expresión normalizada porque de ese modo.

«las consecuencias de su ilegal proceder resultaban imprevisibles para [los recurrentes], en cuanto no podían prever qué tipo de infracción habría de resultar de su conducta y, en consecuencia, qué sanción podría llevar ésta aparejada» ${ }^{5}$.

4 A pesar de esta declaración, el Tribunal consideró, no obstante, innecesario elevar al Pleno la correspondiente cuestión de inconstitucionalidad en relación con el primer párrafo del art. 39.1 LCEN de conformidad con el art. 55.2 LOTC. En esta ocasión al advertir la existencia de una interpretación del citado precepto legal conforme con el art. 25.1 CE. Según razonó entonces, la remisión de la calificación de las infracciones a un momento posterior de la calificación de las infracciones «no necesariamente ha de entenderse hecha al momento de aplicación del mismo, sino que [puede serlo] a una norma posterior en la que se proceda a una precisa determinación de la correspondencia entre infracciones y sanciones».

5 Incidentalmente, importa anotar que en el caso examinado por la citada STC 210/2005 el recurrente fue sancionado por dos infracciones, que la Administración calificó respectivamente de grave y leve. En aplicación de la doctrina recordada en el texto, el Tribunal anuló la sanción por la primera de las infracciones y mantuvo, sin embargo, la impuesta por la infracción leve. Literalmente porque, «la calificación de la infracción en la categoría más liviana no causa un perjuicio efectivo y real al demandante de amparo, en la medida en que tal calificación sí era previsible [...]». Una idea que poco después renovará la STC 129/2006, de 24 de abril (FJ 4), al hilo de resumir la doctrina constitucional sobre el mandato de taxatividad. 
Años después, la STC 166/2012, de 1 de octubre, utiliza este mismo razonamiento para estimar la cuestión de inconstitucionalidad planteada en relación con el art. 30 de la Ley del Parlamento de Cataluña 3/1993, de 5 de marzo, del Estatuto del Consumidor, también anotado al principio.

Sirviéndose una vez más de la declaración que ya conocemos por las sentencias anteriores sobre la calificación ad hoc de las infracciones, el Tribunal Constitucional concluye igualmente que en este otro caso el precepto autonómico cuestionado.

«traslada la calificación de las infracciones a un momento aplicativo posterior y, por ende, externo a la previsión legal en contra de la vertiente material del derecho a la legalidad sancionadora recogido en el art. 25.1 CE» (FJ 5).

El mismo criterio utiliza asimismo la STC 10/2015, de 2 de febrero, para estimar la cuestión de constitucionalidad promovida en relación ahora con el art. 50.1 LCU, y que la citada sentencia declara efectivamente inconstitucional y nulo por vulnerar la vertiente material del derecho a la legalidad sancionadora del art. 25.1 CE.

En particular, la citada sentencia recuerda que.

«la necesidad de que la ley predetermine suficientemente las infracciones y las sanciones, así como la correspondencia entre unas y otras, no implica un automatismo tal que suponga la exclusión de todo poder de apreciación por parte de los órganos administrativos a la hora de imponer una sanción concreta, pero en modo alguno cabe encomendar por entero tal correspondencia a la discrecionalidad judicial o administrativa, ya que ello equivaldría a una simple habilitación en blanco a la Administración por norma legal vacía de contenido material propio. Consecuentemente, el artículo 25.1 CE limita, no ya el ejercicio administrativo de la discrecionalidad, sino su atribución misma por parte del legislador».

Y dicho esto, declara que el precepto legal cuestionado vulnera efectivamente el art. 25.1 CE, empleando literalmente la misma y sumaria declaración de la STC 166/2012 que acaba de transcribirse.

Como, en fin, está es igualmente la ratio decidendi que utiliza la mucho más moderna STC 150/2020, de 22 de octubre, para estimar ahora la cuestión de inconstitucionalidad promovida contra el art. 40 de la Ley Foral 7/2006 por vulneración asimismo del art. 25.1 CE.

El precepto cuestionado, en su versión original, que fue la considerada en el proceso judicial a quo, establecía en términos que ya nos son familiares que.

«las infracciones se calificarán de leves, graves o muy graves en función de la concurrencia de los siguientes criterios: a) Daño o riesgo para la salud o seguridad de los consumidores. b) Lesión de los intereses económicos de los consumidores. c) Grado de vulnerabilidad de los destinatarios del producto o servicio. d) Número de afectados. e) Alteración social producida. f) Cuantía del beneficio ilícito obtenido, en relación con el valor del bien o servicio. g) Concurrencia de dolo o culpa. h) Posición en el mercado del infractor. i) Existencia o no de reincidencia y, en su caso, reiteración de la conducta infractora. j) Volumen de ventas del infractor».

El órgano judicial promotor cuestionó este precepto con fundamento en la exigencia de taxatividad o de lex certa del art. 25.1 CE razonando que no permitía conocer de antemano la calificación de las infracciones y, en consecuencia, saber con la necesaria precisión cómo serían finalmente castigadas, supuesto que a medida que se asciende en la escala de gravedad de las infracciones se incrementa también el quantum y el rigor de las sanciones.

Con arreglo a este planteamiento, la sentencia, después de repasar lo principal de su propia doctrina sobre este mismo núcleo de problemas, declara que,

«a la vista de la tipificación de infracciones que realiza la ley foral, el ciudadano, aunque pueda identificar de antemano qué conductas son sancionables, desconoce o no puede saber con la precisión suficiente cómo van a castigarse. Al abandonar la calificación de la gravedad de las infracciones al momento aplicativo, se deja en gran medida en manos de la Administración la determinación del tipo de sanción (amonestación o multa) y, en el caso de las pecuniarias, la entera concreción de su alcance, pues la horquilla establecida es amplísima (entre el mínimo de $0,1 €$ previsto para las infracciones leves; y los $600.000 €$ establecidos como máximo para las muy graves)». 
De manera que:

«Puede concluirse así que el art. 40 de la Ley 7/2006 no garantiza mínimamente la seguridad jurídica de los administrados, dado que estos ignoran las consecuencias que han de seguirse por la realización de una conducta tipificada como infracción en dicha norma. En consecuencia, procede la declaración de inconstitucionalidad del art. 40 de la Ley Foral 7/2006 y su declaración de nulidad».

\section{OBSERVACIONES CRÍTICAS A LA PROHIBICIÓN DE LA CLASIFICACIÓN AD HOC DE LAS INFRACCIONES}

La conclusión de la jurisprudencia que acaba de resumirse, con la doctrina constitucional al frente, es desde luego terminante: la ley no puede descargar la clasificación de las infracciones en la propia Administración sancionadora, por impedirlo el principio de legalidad sancionadora del art. $25.1 \mathrm{CE}$, en su vertiente material.

Esta rotunda prohibición me parece, sin embargo, que no está muy bien calibrada y presenta, en cualquier caso, tantos desgarrones que al final aprieta más bien poco. De hecho, como luego también podrá verse, el legislador administrativo estatal y autonómico, y de todos los sectores, no parece muy dispuesto a respetarla, al menos a rajatabla.

Las debilidades de esta declaración constitucional me parecen, en efecto, tan llamativas que me sorprende que nadie hasta ahora se haya decidido a denunciarlas y haya advertido que en este tipo de asuntos el principio de legalidad sancionadora camina desnudo, por mucho que el Tribunal Constitucional se haya empeñado en ver y declarar lo contrario. Y para probarlo se me ocurren media docena de observaciones.

\section{Una declaración constitucional sumaria y sin apenas explicación}

Para empezar, si se repasan nuevamente las sentencias constitucionales anotadas podrá verse enseguida que el Tribunal Constitucional formula la prohibición que ya conocemos en forma bastante sumaria y, en todo caso, sin apenas pararse a argumentarla.

Sobre el principio de legalidad sancionadora del art. 25.1 CE existe conocidamente una abundantísima y consolidada doctrina constitucional, de la que son buena muestra, entre otras muchas, las SSTC 219/1989, de 21 de diciembre; 113/2002, de 9 de noviembre; 260/2007, de 20 de diciembre; y 145/2013, de 11 de julio.

En lo que ahora únicamente nos interesa, en esa doctrina está dicho que la necesidad de que la ley predetermine suficientemente las infracciones y sanciones, así como la correspondencia entre unas y otras, «no implica un automatismo tal que suponga la exclusión de todo poder de apreciación por parte de los órganos administrativos a la hora de imponer una sanción concreta». De manera que la ley «puede dejar márgenes más o menos amplios a la discrecionalidad administrativa», siempre que no quede "encomendada por entero a ella». Pues, en ese caso, «ello equivaldría a una simple habilitación en blanco a la Administración por norma legal vacía de contenido material propio».

Conforme muy bien resume la reciente STC 14/2021, de 28 de enero:

«La garantía material implica que la norma punitiva permita predecir con suficiente grado de certeza las conductas que constituyen infracción y el tipo y grado de sanción del que puede hacerse merecedor quien la cometa, lo que conlleva que no quepa constitucionalmente admitir formulaciones tan abiertas por su amplitud, vaguedad o indefinición, que la efectividad dependa de una decisión prácticamente libre y arbitraria del intérprete y juzgador».

Teniendo en cuentas estas declaraciones, que las propias sentencias anotadas se encargan además de recordar, y prescindiendo en este momento del supuesto de la STC 207/1990, que es algo distinto, para ser riguroso, el razonamiento del Tribunal debió comenzar en todos los casos vistos por comprobar precisamente si el precepto legal cuestionado en cada caso (fuera el art. 39.1 LCEN, en el primer grupo de sentencias; o fueran los respectivos artículos de las leyes estatal, catalana o foral en materia de defensa y protección de los consumidores, en el otro grupo) contenía criterios capaces de orientar la decisión de la Administración o, si por el contrario, suponía una simple habilitación en blanco vacía de contenido material propio.

En otros términos, advertido que, efectivamente, como ya nos consta, todos los preceptos legales hasta ahora cuestionados condicionaban el ejercicio de la facultad de la Administración para calificar la corres- 
pondiente infracción a la valoración de determinados criterios, el Tribunal debió comenzar por ver si esos criterios legales eran suficientes para orientar la decisión de la Administración y, por tanto, satisfacían o no la exigencia material de predeterminación normativa de las infracciones.

Curiosamente, sin embargo, si volvemos otra vez a las sentencias constitucionales anotadas podrá comprobarse que ese razonamiento no existe rigurosamente por ningún lado.

No está ya, para empezar, en la decisiva STC 100/2003, de 2 de junio, que, con el antecedente de la citada STC 207/1990, inaugura la serie de pronunciamientos del Tribunal a propósito de este tipo de asuntos, y a la que simplemente siguen todas las demás, sin ningún añadido de interés.

De hecho, para decir toda la verdad, habría que añadir que en esa ocasión el Tribunal termina por airear sus propias debilidades. Puesto que, después de declarar con toda solemnidad, a la vista del contenido del art. 39.1 LCEN entonces cuestionado, que «[la] remisión [que contiene] no es incondicionada, toda vez que el legislador proporciona una serie de criterios», concluye paradójicamente a renglón seguido y sin más explicaciones que la «graduación de las sanciones y la calificación ad hoc de las infracciones no resulta acorde con el principio de taxatividad» (FJ 6). Realmente no es difícil pensar en otra forma de razonar más ajustada a pautas metodológicas más rigurosas.

Peor es, si cabe, el saldo de las sentencias posteriores en las que el Tribunal ya no se preocupa siquiera de reparar en esa elemental comprobación y en sus posibles consecuencias, y que inexplicablemente decide silenciar por completo. Solo al final, en la última STC 150/2020, ha parado en esa decisiva cuestión, bien que para pasar de puntillas y advertir simplemente que el precepto cuestionado (entonces el art. 40 de la Ley Foral 7/2006),

«se limita a enumerar diez criterios distintos en función de los cuales la administración podrá decidir si la infracción es leve, grave o muy grave. Pero no establece ninguna relación entre la concurrencia de dichos criterios y la calificación de la infracción en alguno de los tres grados que prevé. Y esta indeterminación se ve agravada por el hecho de que los criterios que el art. 40 recoge para graduar la infracción (como leve, grave y muy grave) son los criterios a los que también el art. 42.2 remite para la graduación de la sanción» (FJ 4).

Enseguida volveré sobre esta declaración, que de todas formas adelanto no me parece convincente. En este momento, me interesa únicamente notar que las sentencias anotadas dan cuenta de un curioso comportamiento del Tribunal. A fuerza de repetir sus declaraciones, en la doctrina constitucional es hoy poco menos que incontrovertible que la ley no puede en ningún caso descargar en la Administración la gradación de las infracciones. Ni siquiera tampoco cuando el legislador condiciona normativamente esa tarea a la valoración de determinados criterios. Algo así, en fin, como que la inconstitucionalidad de esa forma de tipificación de las infracciones administrativas fuera tan manifiesta que no necesitara ya de ninguna explicación.

Este déficit de motivación no es fácil de justificar y, en cualquier caso, no es tampoco el que resulta directamente de la aplicación de la propia doctrina constitucional al respecto, que sólo prohíbe, como ya nos consta, las habilitaciones legales en blanco, huérfanas de todo contenido normativo propio, pero no cualquier indeterminación normativa ni, por tanto, toda remisión del legislador en favor de la Administración para que decida sobre la gravedad de la infracción o sobre la sanción a imponer.

\section{La distinta vara de medir la graduación de las infracciones y de las sanciones}

La prohibición comentada se entiende todavía peor si se compara con la doctrina constitucional en materia de graduación de las sanciones, y que contrariamente, como enseguida se insistirá, admite con absoluta naturalidad la posibilidad de que el legislador remita a la Administración la determinación de la sanción a imponer, sin que esa remisión legal suponga desde luego, menos aún por principio, ninguna quiebra de las exigencias de predeterminación normativa y certeza que imponen los principios de legalidad sancionadora y seguridad jurídica de los arts. 25.1 y $9.3 \mathrm{CE}$.

Conocidamente, en nuestro ordenamiento jurídico abundan y son absoluta mayoría las leyes sancionadoras que remiten la determinación de la concreta sanción aplicable a la correspondiente decisión singular de la Administración, dentro de los límites señalados en la ley, normalmente mediante la utilización de una horquilla, las más de las veces formulada con expresión de unos márgenes mínimo y máximo, y con arreglo a los criterios de gradación que la misma ley asimismo acostumbra a precisar. 
De la larga lista de leyes sancionadoras que se ajustan a ese esquema, es el caso, por ejemplo, de la Ley Orgánica 4/2015, de 30 de marzo, de protección de la seguridad ciudadana, muy posiblemente además una de las normas sancionadoras más veces aplicada por la Administración y cuyo art. 33.2 establece que, para la graduación de la multa correspondiente,

«[...] se tendrán en cuenta los siguientes criterios: a) la entidad del riesgo producido para la seguridad ciudadana o la salud pública; b) la cuantía del perjuicio causado; c) la trascendencia del perjuicio para la prevención, mantenimiento o restablecimiento de la seguridad ciudadana; d) la alteración ocasionada en el funcionamiento de los servicios públicos o en el abastecimiento a la población de bienes y servicios; e) el grado de culpabilidad; f) el beneficio económico obtenido como consecuencia de la comisión de la infracción; y g) la capacidad económica del infractor» ${ }^{6}$.

Esta forma de tipificar las sanciones es, en efecto, absolutamente dominante $y$, de hecho, son contadas las leyes sancionadoras que fijan con precisión la sanción que corresponde a cada una de las infracciones que tipifica ${ }^{7}$. Pero también, y lo que ahora es más importante, perfectamente constitucional, según lo confirma la doctrina del Tribunal, que nunca ha advertido ninguna tacha de tipicidad en cualquiera de las leyes sancionadoras que remiten a la decisión de la Administración la determinación del quantum sancionador.

Está así dicho, en efecto, en una unánime doctrina constitucional, de la que son buena muestra las SSTC 175/2012, de 15 de octubre (FJ 3); 145/2013, de 11 de julio (FJ 8), y 14/2021, de 28 de enero (FJ 6), cuando usando la misma fórmula declaran que.

«resulta compatible con la garantía del principio de legalidad sancionadora que el legislador atribuya discrecionalidad a la Administración dentro de unos límites para concretar el alcance o importe de la sanción».

Sin abandonar esta misma comparación, pero desde otra perspectiva, importa subrayar que leyes sancionadoras las hay incluso, y en buen numero además, que habilitan a la Administración, no ya para que, como es más habitual y testimonian los ejemplos citados, determine el quantum o el alcance de la concreta sanción a imponer con sujeción a los límites y criterios que previamente ha fijado la misma ley, sino para que seleccione, entre los tipos de sanciones legalmente previstas, la que mejor conviene para corregir la infracción cometida, incluso de forma acumulada.

De los muchos ejemplos de leyes de este tipo que ahora también podrían citarse ${ }^{8}$, baste en este momento con anotar los tres siguientes, que están tomados además de la propia jurisprudencia del Tribunal Constitucional.

Según el art. 89.1 de la Ley 8/1990, de Caza de Extremadura, las infracciones leves «serán sancionadas con multa [...], pudiendo llevar implícita la retirada de la licencia [de caza] o la imposibilidad de obtenerla por un plazo de 1 a 2 años».

El art. 67.1 del anterior Texto articulado de la Ley de Tráfico, aprobado por Real Decreto Legislativo 339/1990, de 2 de marzo, precisaba para el caso de las infracciones graves que, además de la correspondiente multa, «podrá imponerse la sanción de suspensión del permiso o licencia de conducción por el tiempo mínimo de un mes y máximo de tres meses».

Y el art. 57.1 de la Ley Orgánica 8/2000, de 22 de diciembre, sobre derechos y libertades de los extranjeros en España, establece que para corregir las infracciones muy graves y determinadas infracciones graves que el propio precepto identifica, «podrá aplicarse, en atención al principio de proporcionalidad, en lugar de la sanción de multa, la expulsión del territorio español, previa la tramitación del correspondiente expediente administrativo y mediante resolución motivada que valore los hechos que configuran la infracción».

6 Sin apurar demasiado, salpicados por el ordenamiento se pueden encontrar con facilidad otros muchos testimonios. Con pequeñas variantes, la misma regla sobre criterios de gradación de las sanciones es la que establecen, por ejemplo: Ley $37 / 2003$, de 17 de noviembre, del Ruido (art. 29.3); Ley 43/2003, de 21 de noviembre, de Montes (art. 75); Ley 29/2006, de 26 de julio, de Garantías y Uso Racional de los Medicamentos y Productos sanitarios (art. 102.1); Ley 15/2007, de 3 de julio, de Defensa de la Competencia (art. 64.1); Ley 42/2007, de 13 de diciembre, del Patrimonio Natural y de la Biodiversidad (art. 81.2); Texto Refundido de la Ley de EvaIuación de Impacto Ambiental de Proyectos, aprobado por Real Decreto Legislativo, 1/2008, de 11 de enero (art. 21.2); Ley 13/2011, de 27 de mayo, de regulación del juego (art. 42.6); Texto Refundido de la Ley de Puertos y de la Marina Mercante, aprobado por Real Decreto Legislativo 2/2011, de 5 de septiembre (art. 314); Ley 5/2014, de 4 de abril, de Seguridad Privada (art. 64).

7 Cfr., Nieto (2012, p. 511); Cano (2018, pp. 144 y ss.); e Izquierdo (2001 pp. 218-221).

8 Probablemente el art. 105.1 de la Ley 3/2001, de Pesca, sea uno de los ejemplos más llamativos porque contempla hasta doce tipos de sanciones que pueden «imponerse con carácter principal, acumulándose cuando proceda». 
Los citados preceptos legales fueron objeto respectivamente de una cuestión de inconstitucionalidad y de sendos recursos de inconstitucionalidad. Tanto el auto de planteamiento en el caso del art. 67.1 de la antigua Ley de Tráfico, como los recursos de inconstitucionalidad promovidos en los otros dos, defendieron con parecidos argumentos que la respectiva fórmula utilizada («pudiendo», en el primer caso, y "podrá» en los otros dos) concedía a la Administración un excesivo margen de discrecionalidad para decidir libremente sobre la concreta sanción a imponer, que resultaba de ese modo imprevisible para su destinatario y, por tanto, contraria a la exigencia de predeterminación normativa («lex certa» y «lex previa») de las sanciones que garantiza el art. 25.1 CE.

El Tribunal Constitucional, usando la misma argumentación, declaró sin embargo en los tres casos que el respectivo precepto recurrido.

«cumple con las exigencias de predeterminación normativa y certeza que se derivan de los principios de legalidad y seguridad jurídica consagrados en los arts. 25.1 y $9.3 \mathrm{CE}$, pues la imposición de la sanción [de retirada de la licencia de caza, de suspensión del permiso o licencia de conducir o de expulsión, según cada caso] no depende de la absoluta discrecionalidad de la Administración ni es una facultad enteramente libre, sino que está condicionada, además de por la existencia de una infracción [tipificada], por la concurrencia de los criterios establecidos en la propia Ley, [que] son criterios perfectamente definidos y objetivados que condicionan normativamente la actuación de la Administración y que permiten la revisión jurisdiccional de la decisión que, en cada caso, hubiese alcanzado» (SSTC 14/1998, de 22 de enero, FJ 10; 113/2002, de 9 de mayo, FJ 7; y 260/2007, de 20 de diciembre, FJ 4, respectivamente).

Una declaración, en particular, sobre la que el Tribunal ha vuelto en repetidas ocasiones con motivo de distintos recursos de amparo interpuestos contra otras tantas sanciones administrativas de expulsión acordadas en aplicación del citado art. 57.1 de la Ley Orgánica 8/2000. Y siempre para subrayar en expresión ya normalizada que.

«la imposición de la sanción de expulsión no depende de la absoluta discrecionalidad de la Administración, sino que la ley establece unos presupuestos objetivos y subjetivos, así como unos criterios de aplicación que condicionan normativamente a la Administración» (SSTC 140/2009, de 15 de junio, FJ 3; 212/2009, de 26 de noviembre, FJ 4; y 145/2011, de 26 de septiembre; FJ 4).

En consecuencia, en el criterio del Tribunal Constitucional, la garantía material del principio de legalidad sancionadora del art. 25.1 CE no prohíbe que el legislador pueda diferir al momento del ejercicio de la potestad sancionadora la precisión de la concreta sanción a imponer, siempre que al hacerlo condicione normativamente la decisión administrativa.

\section{No hay razones para la distinción y la esencialidad de la sanción}

De la mano de estas declaraciones constitucionales una conclusión salta inmediatamente a la vista. Hasta la fecha, el Tribunal Constitucional ha observado la exigencia de tipificación legal de las infracciones con notable mayor rigor que el que utiliza cuando ha examinado esa misma exigencia en relación con las sanciones.

En estas condiciones, es lógico preguntarse si existe alguna razón que constitucionalmente justifique semejante distinto tratamiento. Atender a este interrogante es, además, tanto más obligado desde el momento en que, como también demuestra la realidad, no faltan precisamente los supuestos en los que la ley utiliza los mismos criterios para uno y otro caso ${ }^{9}$.

Sin ir más lejos, es el caso, por ejemplo, del citado art. 39.4 LCEN cuando advertía que «los criterios establecidos en el primer apartado de este artículo [para calificar la correspondiente infracción de leve, grave o muy grave] se tendrán en cuenta para graduar la sanción que se imponga dentro del intervalo correspondiente a cada infracción». La misma regla podía leerse también en el art. 42.2 de la Ley Foral 7/2006, en la versión enjuiciada por la comentada STC 150/2020, al disponer que «para la determinación de la cuantía

9 Esta fórmula plantea, no obstante, desde la perspectiva de la prohibición de bis in idem, la cuestión de la posible doble utilización de un mismo criterio; primero para agravar la infracción y, más tarde, en segundo lugar, para agravar también la sanción. Al respecto, cfr., Nieto (2012, pp. 515-516). 
pecuniaria de la sanción se tendrá en cuenta lo dispuesto en el artículo 40 de la presente Ley Foral [para calificar las infracciones]».

No existe, sin embargo, en la doctrina constitucional ninguna razón que permita pensar que la tipificación normativa de las infracciones deba observar un canon de control distinto ni más riguroso que el que rige en materia de tipificación de las sanciones. Sí abundan, en cambio, las declaraciones del propio Tribunal que destacan esa doble vertiente del mandato de tipificación y, por tanto, que subrayan la identidad de las exigencias que imponen en uno y otro caso el principio de legalidad sancionadora del art. 25.1.

Tal y como afirma la STC 45/1994, de 15 de febrero, «las sanciones, y no sólo las infracciones, se encuentran sometidas al principio constitucional de legalidad» (FJ 5). Por su parte, la STC 113/2002, de 9 de mayo, deja claro que «la garantía impuesta por el art. 25.1 CE no se refiere solo a la tipificación de las infracciones, sino también y en igual medida al establecimiento de las sanciones aplicables» (FJ 4); Y esta misma es también, en fin, la declaración que utiliza la reciente STC 14/2021, de 28 de enero, para insistir en que «la doble garantía, formal y material, impuesta por el art. 25.1 CE no se refiere solo a la tipificación de las infracciones, sino también, y en igual medida, al establecimiento de las sanciones aplicables» (FJ 6).

De modo congruente, y una vez admitido que la determinación normativa de las sanciones está efectivamente sujeta a las mismas exigencias de certeza y seguridad jurídicas que la tipificación legal de las infracciones, lo lógico es preguntarse a continuación ¿por qué entonces aquéllas sí, y éstas no, pueden ser determinadas por la Administración sancionadora en el proceso de aplicación de la ley con sujeción a los criterios graduación fijados por la propia norma? En otros términos: ¿por qué la habilitación legal que consideramos en favor de la Administración (la remisión a un momento aplicativo posterior, por seguir la expresión que utiliza el Tribunal) es constitucionalmente legítima cuando se trata de graduar sanciones y no lo es, en cambio, cuando se trata de graduar infracciones?

A poco que se observe podrá verse que estos interrogantes tienen una apariencia algo inquietante para la doctrina del Tribunal Constitucional y dejan, en cualquier caso, en bastante mal lugar a las sentencias que han afirmado que la remisión de la graduación de las infracciones a un momento posterior no es sencillamente posible.

Esa doble vara de medir que utiliza el Tribunal resulta, por otra parte, aún más difícil de explicar si se tiene en cuenta ahora que, en este tipo de casos, (en los que no se cuestiona la tipificación o la predeterminación normativa de las infracciones -dimensión o vertiente del principio de tipicidad que está satisfecha cuando la ley, como sucede en todos los casos examinados, tipifica por sí misma las conductas ilícitas-, sino únicamente la calificación de esas infracciones en alguna de las categorías de leve, grave o muy grave), lo que al final está verdaderamente en juego es la determinación de la concreta sanción, supuesto que a medida que se asciende en la escala de calificación de la infracción se agrava también el castigo correspondiente.

De modo que, apurando el planteamiento, la imprevisibilidad o inseguridad jurídica que plantea esta forma de tipificación de las infracciones se resume, a fin de cuentas, en un problema de incertidumbre sobre la sanción a imponer. Lo que a la postre significa que la imprecisión que consideramos está más bien en el segundo tramo del binomio infracción-sanción y apunta, en consecuencia, más a la certeza y seguridad de las sanciones que a la tipicidad de las infracciones ${ }^{10}$.

Las propias sentencias constitucionales anotadas así parecen confirmarlo cuando justifican su reproche en el hecho de que, con arreglo a esa forma de tipificar las infracciones, el interesado no es que desconozca el carácter ilícito de su conducta, es que no puede conocer con la precisión suficiente el grado o el alcance de sus consecuencias sancionadoras. Las declaraciones de la citada STC 150/2020 que al principio se han recordado son un buen ejemplo, en la medida que ponen el acento en la dificultad de que el ciudadano pueda saber con seguridad cómo va a castigarse su conducta.

Por esta misma razón se comprende mejor que la STC 210/2005, también antes vista, decidiera confirmar la sanción impuesta por la comisión de una infracción que la Administración calificó entonces de leve en aplicación del art. 39.1 LCNE razonando que.

10 En este contexto, es razonable la crítica que certeramente formula Izquierdo (2001, p. 221), cuando advierte que, a diferencia del derecho penal, «en el derecho administrativo, la calificación del grado de gravedad de la infracción no se hace depender de la sanción que lleva pareja, sino del caprichoso y voluntarista criterio del legislador [...]». Como el propio autor precisa un poco más adelante (Izquierdo, 2001, p. 226), esta libertad normativa es la que explica que el legislador sectorial pueda establecer la misma sanción para castigar infracciones que «para una ley sea leve, para otra grave y para otra muy grave». Para corregir esta desviación, el citado autor defiende que, «el único elemento que puede calificar externamente la gravedad de una infracción es su penalidad» (Izquierdo, 2091, p. 222). En el mismo sentido, Cano (2018, pp. 124-125). 
«siendo cierto que el mismo reproche merece que se difiera por completo al momento aplicativo la gravedad de la infracción, también lo es que la calificación de la infracción en la categoría más liviana no causa un perjuicio efectivo y real al demandante de amparo, en la medida en que tal calificación [y su consecuencia sancionadora] sí era previsible».

Todo lo cual renueva aún más la necesidad de dar una respuesta a los interrogantes que antes he dejado formulados y para lo que lamentablemente las sentencias que hemos repasado no sirven.

\section{El tamaño de la horquilla sancionadora y sus consecuencias}

Antes de seguir adelante, creo conveniente subrayar lo siguiente: no ignoro que la existencia de un margen de apreciación en manos de la Administración es precisamente una de las principales razones de la censura que formulan las sentencias que hemos repasado y que es particularmente visible en la STC 150/2020 que, como se recordará, declara que, a con arreglo a esa forma de tipificación de las infracciones, el ciudadano.

«desconoce o no puede saber con la precisión suficiente cómo van a castigarse. Al abandonar la calificación de la gravedad de las infracciones al momento aplicativo, se deja en gran medida en manos de la administración la determinación del tipo de sanción (amonestación o multa) y, en el caso de las pecuniarias, la entera concreción de su alcance, pues la horquilla establecida es amplísima (entre el mínimo de $0,1 €$ previsto para las infracciones leves; y los $600.000 €$ establecidos como máximo para las muy graves)».

Este mismo argumento es el que utiliza la reciente STC 14/2021, de 28 de enero, para desestimar la cuestión de inconstitucionalidad planteada por parecidos motivos contra el art. 153.1 de Ley Orgánica 5/1985, de 19 de junio, del Régimen Electoral General (LOREG). Este precepto establece que.

«toda infracción de las normas obligatorias establecidas en la presente Ley que no constituya delito será sancionada por la Junta Electoral competente. La multa será de 300 a 3.000 euros si se trata de autoridades o funcionarios y de 100 a 1.000 si se realiza por particulares».

Para el órgano judicial proponente de la cuestión, el citado precepto, en la medida que no especifica ni gradúa las infracciones, distinguiendo entre infracciones muy graves, graves o leves, habilita a la Administración sancionadora para que establezca ad hoc la sanción que tenga por conveniente, con consecuente vulneración de la exigencia de lex certa del art. 25.1 CE. Es decir, en resumidas cuentas, la misma infracción constitucional denunciada en todos los casos que hemos repasado hasta ahora.

En esta ocasión, sin embargo, el Tribunal Constitucional afirma, sirviéndose de la declaración de la STC 150/2020 que antes he recordado, que a diferencia de lo que entonces sucedía en este otro caso.

«el establecimiento en cada uno de los supuestos recogidos en el art. 153.1 LOREG de una horquilla, en la que la cantidad mínima y la máxima se encuentran cuantitativamente tan cercanas, no puede considerarse que no garantice mínimamente la seguridad jurídica de los ciudadanos, que no ignoran las consecuencias que han de seguirse de la realización de una conducta legalmente tipificada como infracción administrativa. No existe, como en otras ocasiones ha ocurrido, un amplísimo margen de apreciación en la fijación del importe de la multa que se puede imponer al infractor por el órgano sancionador, al que, de acuerdo con la doctrina referida, cabe reconocerle legalmente una cierta facultad discrecional en la individualización de la sanción».

Aunque esta última sentencia parece corregir parcialmente el rumbo de las anteriores, me parece que no es posible ver esa rectificación. De hecho, opino que esta sentencia confirma la debilidad de la doctrina constitucional dictada a propósito del asunto que nos interesa, en la medida que termina por reducir el juicio sobre la constitucionalidad de esta forma de tipificar las infracciones a una simple cuestión cuantitativa. De manera que, según esa forma de razonar, si el margen o la horquilla de las sanciones en que desemboca la falta de graduación de las infracciones es cuantitativamente apreciable, entonces la norma no es constitucional, porque no garantiza la seguridad jurídica de los ciudadanos. Naturalmente, en caso contrario, si el margen de apreciación de la Administración es en cambio reducido, porque la horquilla sancionadora es estrecha, la solución entonces habrá de ser justo la contraria. 
Realmente cuesta trabajo leer este grupo de sentencias y comprobar que el núcleo de problema de la incerteza o inseguridad jurídicas sobre la clasificación de las infracciones tenga principalmente que ver con el tamaño de la horquilla sancionadora que la ley deja en manos de la Administración para castigarlas. Admito que, en ocasiones, ese pueda ser un elemento a ponderar en el juicio del Tribunal. Pero no desde luego el único ni, menos aún, el decisivo desde la perspectiva del mandato de tipificación que ahora particularmente nos interesa.

Según se ha subrayado, el principal interrogante que plantea esta forma de tipificación de las infracciones no mira a la holgura de la horquilla sancionadora. Apunta directamente a comprobar si el margen del que dispone la Administración para clasificar la infracción y determinar su sanción está normativamente condicionado en forma suficiente o, por el contrario, es de libre apreciación.

De modo congruente, el que la horquilla sancionadora prevista en la ley sea más o menos amplia no constituye a mi juicio ningún canon de control de constitucionalidad de la fórmula de tipificación que consideramos. Por lo mismo, la posibilidad de que, con arreglo a esa forma de tipificación de las infracciones, la Administración pueda finalmente recorrer toda la horquilla sancionadora prevista legalmente e imponer desde la sanción mínima señalada para las infracciones leves a la máxima prevista para las muy graves, no convierte tampoco a la ley en inconstitucional. Por añadidura, importa notar que en el ordenamiento administrativo horquillas sancionadoras las hay, y muy amplias, además, incluso dentro del mismo escalón o grado de infracciones, sin que hasta el momento hayan recibido ningún reproche por ese motivo ${ }^{11}$.

En resumidas cuentas, la constitucionalidad de esta forma de tipificar las infracciones administrativas no refiere una simple cuestión de grado o cantidad, sino de naturaleza. Debe insistirse: al igual que sucede con la tipificación de las sanciones, la remisión a la Administración para que califique de cada vez la gravedad de la correspondiente infracción será constitucionalmente válida si el arbitrio que la ley le concede permite prever razonablemente con el suficiente grado de certeza la correspondiente decisión. En caso contrario, la ley no superaría este test de control y justificaría, en consecuencia, su anulación.

De manera que la verdadera cuestión está, pues, en ver si la remisión que hacen las leyes para que sea la Administración la que, con arreglo a los criterios que la propia ley establece, califique la gravedad de la correspondiente infracción es una fórmula constitucionalmente admisible o si, por el contrario, equivale a una habilitación legal en blanco, que convierte en realmente imprevisibles para el ciudadano las consecuencias jurídicas de su conducta.

\section{Los criterios legales, el margen administrativo de apreciación y la inseguridad}

Mi opinión es la de que esa forma de tipificar las infracciones no solo es perfectamente válida, sino que es también la más conveniente. Por eso el legislador la utiliza con mucha más frecuencia de la que pudiera pensarse, según luego se verá con más detalle.

Por lo pronto, es jurídicamente irreprochable porque la calificación en cada caso de la gravedad de la correspondiente infracción no depende de la libre discrecionalidad de la Administración, sino que está limitada, de un lado, por la existencia de una infracción previa, tipificada en la ley, y, de otro, por la necesaria atención a los criterios legales de graduación que todas las leyes examinadas se preocupan de precisar. De tal manera que la suma de estos dos presupuestos convierte en razonablemente previsible para el infractor la calificación de la gravedad de su conducta y la determinación de sus consecuencias sancionadoras. Todo ello, como es natural, sin perjuicio de la exigencia de que la Administración motive su aplicación en cada caso, y de la posibilidad del posterior control jurisdiccional de la correspondiente decisión.

No es, por tanto, que la descarga en la Administración de la clasificación ad hoc de las infracciones se produzca en blanco o de forma incondicionada, ni que el infractor pueda desconocer simplemente las consecuencias de su comportamiento, como sin embargo ha afirmado el Tribunal Constitucional. Es justo lo contrario: cualquiera de las fórmulas legales examinadas cumple el mandato de tipificación de las infracciones.

Si volvemos ahora a las leyes estatal y autonómicas sobre consumidores y usuarios (que son, por otra parte, las más inclinadas a servirse de esta fórmula de tipificación de las infracciones, según confirman las

11 Para probarlo sirvan los siguientes dos botones de muestra. Según el art. 36.1 c) de la Ley 14/1986, de 25 de abril, General de Sanidad, las infracciones muy graves serán sancionadas con multa desde 2.500 .001 a 100.000 .000 de pesetas [de $15.001 €$ a $600.000 € \ldots .$. . Por su parte, el art. 75.1 de la Ley 14/2007, de 3 de julio, de Investigación biomédica, establece que «[...] las infracciones muy graves serán sancionadas con multa desde 10.001 euros hasta 1.000 .000 de euros». 
leyes de segunda generación aprobadas últimamente ${ }^{12}$ ), podrá confirmarse que todas ellas establecen que la Administración competente clasificará las infracciones tipificadas en la ley atendiendo a determinados criterios. Aunque estos criterios de graduación son variados, los que más veces aparecen son el «riesgo para la salud»; la "posición en el mercado del infractor»; la "cuantía del beneficio obtenido»; el "grado de intencionalidad»; la «gravedad de la alteración social producida»; la «generalización de la infracción»; y la «reincidencia».

Todos ellos son, por tanto, criterios que están fijados normativamente y que tienen, en virtud de su arraigo en la cultura jurídica, un significado sobre el que es muy difícil llegar a confundirse. Todavía más: la mayor parte de ellos coinciden punto por punto con los criterios legales examinados por el propio Tribunal Constitucional a propósito de la graduación administrativa de las sanciones y que, en cambio, ha considerado que condicionan razonablemente la discrecionalidad administrativa.

De cualquier manera que sea, esos criterios permiten conocer con el suficiente grado de certeza las consecuencias sancionadoras de cada infracción porque advierten muy bien que cuanto mayor sean, por ejemplo, la dimensión del riesgo creado, el círculo de personas afectadas por la infracción o el beneficio obtenido con la misma; o, desde otra perspectiva, más dominante sea en cada caso la posición del infractor en el mercado o más veces haya cometido la misma infracción, más grave será también la infracción cometida y, en consecuencia, la sanción que lleva pareja.

Esta es, me parece, una conclusión muy difícil de discutir, casi de puro sentido común, y que solo el rigorismo constitucional y la aplicación inflexible del mandato de tipificación legal han impedido afirmar hasta ahora. Conste en todo caso que, como hemos visto, esta postura rígida se ha impuesto a costa de sacrificar el rigor metodológico y de escamotear las necesarias explicaciones. Pero también a despecho de la realidad y de la racionalidad práctica ${ }^{13}$.

Pues si del mandato de tipificación legal de las infracciones quiere hablarse en rigor, no puede ignorarse, por seguir con el ejemplo que más veces ha salido, que en pocos sectores del ordenamiento la variedad de las posibles conductas ilícitas es tan acusada como en materia de protección de los consumidores y usuarios. Como muy diversa es asimismo la antijuridicidad o el desvalor de las posibles infracciones.

Entre otras razones por culpa de la propia abundancia de los productos, actividades y servicios puestos a disposición de los consumidores y usuarios y de los sujetos que intervienen en el mercado. Pues, al respecto, no es desde luego jurídicamente indiferente que la conducta ilícita tipificada arriesgue la integridad o el funcionamiento de un sencillo producto doméstico que la salud de los consumidores o su patrimonio. Como tampoco lo es que la conducta ilícita afecte a unos pocos ciudadanos que provoque una fuerte conmoción social. Ni que los beneficios obtenidos con la infracción sean reducidos o pingües. O, en fin, que el responsable de la infracción sea un gran empresario que un pequeño comerciante. De tal manera que la gravedad de cada infracción depende finalmente, entre otros criterios, de la naturaleza y las dimensiones del riesgo creado con la infracción, de la cuantía del beneficio obtenido con la misma, o, en fin, de la posición del infractor en el mercado.

En estas condiciones, pretender que la ley agote por sí misma la calificación de la gravedad que mejor cuadra con cada una de las infracciones que tipifica bien parece una exigencia demasiado rigurosa y que puede resultar hasta inconveniente en ocasiones, conforme enseguida se insistirá.

Por el momento baste con subrayar que la necesidad de atender a las circunstancias indicadas prueba la dificultad de que el legislador determine por sí mismo la concreta gravedad de las conductas ilícitas que tipifica. Una dificultad que apunta a la «mayor precisión posible» de la que habla la jurisprudencia y la doctrina científica, con el Tribunal Constitucional nuevamente a la cabeza (últimamente, entre otras, SSTC 160/2019, de 12 de diciembre; 81/2020, de 15 de julio; 172/2020, de 19 de noviembre; y 13/2021, de 28 de enero), y que, de modo congruente, apela a la necesidad de huir de exigencias maximalistas ${ }^{14}$.

12 Cfr. la Ley 16/2006, de 28 de diciembre, de Protección y Defensa de los Consumidores y Usuarios de Aragón (arts. 81 y ss.); la Ley 2/2015, de 4 de marzo, por la que se aprueba el Estatuto del Consumidor de Castilla y León (art. 42); y la Ley 22/2010, de 20 de julio, del Código de consumo de Cataluña (art. 332).

13 La STC 219/1989, de 21 de diciembre, confirma la constitucionalidad de la sanción colegial impuesta a un arquitecto por la comisión de una infracción que el Colegio calificó de grave, a pesar de que el estatuto colegial aplicado no establecía tampoco una clasificación expresa de las infracciones. A pesar de este silencio, en esa ocasión el Tribunal afirmó que «someter la calificación de las faltas o conductas sancionables como leves, graves o muy graves a la apreciación por los órganos colegiales que, en su caso, ha de ser revisada por los órganos judiciales competentes, no equivale a la absoluta inseguridad jurídica que denuncia el recurrente» (FJ 6).

14 Por todos, Nieto (2012, pp. 259-266). 
Incluso habría que añadir que elementales razones de prudencia o de oportunidad, a las que usualmente apela también la doctrina del Tribunal (entre otras, SSTC 104/2009, de 4 de mayo, FJ 3; 90/2012, de 7 de mayo, FJ 5; y 34/2013, de 4 de febrero, FJ 19), y «que pueden variar en los distintos ámbitos materiales de ordenación», según precisa esa misma jurisprudencia constitucional, aconsejan precisamente más bien lo contrario y sugieren, en efecto, la conveniencia de descargar en la Administración la tarea de medir individualmente la gravedad de cada una de las infracciones cometidas.

Desde esta perspectiva, y supuesta la incapacidad del legislador para calibrar positivamente y en abstracto la gravedad de todas las infracciones que tipifica, ¿no sería mejor que la ley se limite a describir las conductas que considera infracciones y deje en manos de la Administración su posterior calificación como leve, grave o muy grave en función de los oportunos criterios de graduación y a la vista de las circunstancias concurrentes en cada caso? Y, comoquiera que sea, si así decidiera hacerlo, ¿incurriría por este motivo en una imperdonable inconstitucionalidad? ${ }^{15}$.

\section{Una vuelta final por las leyes sancionadoras y una pregunta sobre el futuro}

Por poner solo un ejemplo, «no respetar la luz roja de un semáforo» es una conducta que el Texto Articulado de la Ley de Tráfico de 30 de octubre de 2015 (LTSV) tipifica como infracción grave que está sancionada con multa de $200 €$ [arts. 76 . k) y 80.1]. Pues bien, ¿acaso no sería técnicamente más correcto y más justo también desde el punto de vista de una buena política sancionadora que esa infracción se clasifique de leve, grave o muy grave en función de las singulares circunstancias concurrentes en cada caso y atendiendo a los oportunos criterios legales que miren, por ejemplo, a la entidad del riesgo creado, a la generalización de esa infracción o a los antecedentes del infractor?

Desde esta perspectiva, es que ¿nada significa jurídicamente que un conductor rebase un semáforo en rojo por apenas un segundo o que lo haga por una docena o más?; ¿es lo mismo rebasar un semáforo con paso de peatones o que regula un cruce con abundante tráfico, que otro sin paso de peatones o que no regula ningún cruce y que, de hecho, ni siquiera muy pocos conductores respetan habitualmente? $\mathrm{O}$, en fin, ¿es que nada importa tampoco que el infractor rebase el semáforo en rojo con las calles repletas de peatones y vehículos o que lo haga a primera hora de un domingo o en la noche del 24 de diciembre cuando las calles están desiertas?

Naturalmente, no. Lo que sucede es que el legislador de tráfico, consciente seguramente de los remilgos de la doctrina constitucional, ha decido no operar sobre los tipos infractores y, en su lugar, hacerlo sobre la determinación de las sanciones. El art. $81 \mathrm{LTSV}$ es, en efecto, un buen ejemplo de esta forma de ver las cosas cuando dispone que la sanción de multa prevista en la ley con carácter fijo para cada clase de infracción «podrá incrementarse en un 30 por ciento, en atención a la gravedad y trascendencia del hecho, los antecedentes del infractor y a su condición de reincidente, el peligro potencial creado para él mismo y para los demás usuarios de la vía y al criterio de proporcionalidad».

Esta es una regla muy razonable y que permite encontrar soluciones más ajustadas a las singulares circunstancias de cada infracción, aunque en este caso solo funcione para agravar la respuesta sancionadora dentro de cada escalón infractor, nunca para reducirla ${ }^{16}$. Sea como fuere, puestos a ajustar la respuesta sancionadora a las circunstancias de cada infracción, ¿no es preferible que ese deseable ajuste se produzca en el primer momento, cuando se trata precisamente de clasificar la infracción?

Si se piensa que sí, como aquí se defiende, hay dos formas de hacerlo: o bien la ley clasifica por si misma las infracciones con arreglo a las circunstancias de cada infracción o bien descarga esa operación en la Administración.

15 Téngase en cuenta que, como se recordaba en la nota 1, modelos comparados tan admirados como el alemán no contempla la clasificación de las infracciones según su gravedad. En cualquier caso, importa precisar que el juicio a emitir no es ni puede ser sobre la perfectibilidad o el acierto técnico de la ley. Quiero decir que, aunque se admita que el legislador pudiera apurar algo más y determinar positivamente por sí mismo la gravedad de las infracciones que tipifica, ello no convertiría la norma en inconstitucional. Pues, como ya nos consta por las explicaciones del texto, esta es una conclusión que depende de la comprobación de si la fórmula de tipificación utilizada por la norma permite, o no, prever razonablemente con el suficiente grado de certeza la gravedad de la correspondiente infracción y conocer sus consecuencias sancionadoras.

16 Nótese que cuando el legislador decide confiar la graduación de las infracciones permite que, al hacerlo, la Administración pueda recorrer, hacia arriba o hacia abajo, todos los escalones infractores, desde el leve al muy grave, y, en consecuencia, ajustar mucho mejor la concreta sanción a las circunstancias de la infracción realmente cometida. 
Esta segunda fórmula es la que utilizan las leyes que antes hemos repasado y que el Tribunal Constitucional ha juzgado rigurosamente inadmisible. La primera, es la que siguen por su parte otras muchas leyes de todas las épocas y sectores.

Por anotar ahora solo unos pocos ejemplos, el art. 35 de la Ley General de Sanidad de 25 de abril de 1986 clasifica el mismo hecho como infracción leve, grave o muy grave «atendiendo a los criterios de riesgo para la salud, cuantía del eventual beneficio obtenido, grado de intencionalidad, gravedad de la alteración sanitaria y social producida, generalización de la infracción y reincidencia».

El art. 31.1.d) de la Ley de Industria de 26 de julio de 1992 considera por su parte infracciones muy graves «las tipificadas en el apartado siguiente como infracciones graves, cuando de las mismas resulte un daño muy grave o se derive un peligro muy grave e inminente para las personas, la flora, la fauna, las cosas o el medio ambiente».

La Ley del Ruido de 17 de noviembre de 2003 califica en su art. 28.2 de infracción grave determinados incumplimientos y en el siguiente art. 28.3 clasifica esas mismas conductas como infracción grave cuando «no se haya producido un daño o deterioro grave para el medio ambiente ni se haya puesto en peligro grave la seguridad o la salud de las personas».

Y el art. 43 de la Ley de Promoción de la Autonomía Personal y Atención a las Personas en Situación de Dependencia de 14 de diciembre de 2006 tipifica como infracción una larga lista de conductas para advertir a continuación en el siguiente art. 44.1 que esas mismas infracciones «se clasificarán en leves, graves y muy graves, de acuerdo con criterios de riesgo para la salud, gravedad de la alteración social producida por los hechos, cuantía del beneficio obtenido, intencionalidad, número de afectados y reincidencia».

Más modernamente, el Decreto-ley catalán 30/2020, de 4 de agosto, por el que se establece el régimen sancionador específico por el incumplimiento de las medidas de prevención y contención sanitarias para hacer frente a la crisis sanitaria provocada por la COVID-19, proporciona un nuevo y espléndido ejemplo. Sus disposiciones testimonian muy bien que prácticamente todos los incumplimientos que tipifican constituyen infracciones leves, graves o muy graves según el respectivo incumplimiento «produzca un riesgo o daño leve, grave o muy grave para la salud de la población».

Muy posiblemente todas estas fórmulas legales tranquilicen la conciencia de los juristas más escrupulosos con el mandato de tipicidad y hasta es probable también que logren escapar del control del Tribunal Constitucional. Pero sea como fuere, no logran evitar que al final sea ahora también la propia Administración sancionadora, y no la ley, la que de verdad clasifica las infracciones. A fin de cuentas, porque cualquiera de esos criterios legales es tan abstracto que apenas aprietan algo, de manera que es efectivamente cada acto sancionador el que, a la vista de las circunstancias concurrentes, acaba por incluir cada infracción en la correspondiente categoría general.

De modo que, al final, la inseguridad jurídica que se creía haber expulsado con ese tipo de fórmulas legales vuelve a aparecer intacta en el proceso de aplicación de la norma. Lo que a la postre significa, para escándalo de las tesis más «garantistas» del ciudadano-infractor, que la Administración sancionadora clasifica las infracciones en muchas más ocasiones de las que testimonia la jurisprudencia constitucional. Más todavía: la pregunta es si el Tribunal Constitucional estaría dispuesto a aplicar hasta sus últimas consecuencias su propia doctrina y, por tanto, si, llegado el caso, anularía las abundantes leyes que hay salpicadas por el ordenamiento y que, con una u otra formulación, confían a la Administración la tarea de clasificar las infracciones ${ }^{17}$.

\section{REFERENCIAS BIBLIOGRÁFICAS}

Cano Campos, T. (2018). Sanciones Administrativas (Claves Prácticas de Derecho Administrativo). Francis Lefebvre. Casares Marcos, A. B. (2012). Principio de legalidad y ejercicio de la potestad administrativa sancionadora. Revista

17 Además de los ejemplos anotados en el texto, vid., entre otros muchos, el art. 68 de la Ley de Montes de 21 de noviembre de 2003; el art. 74 de la Ley de Investigación biomédica de 3 de julio de 2007; los arts. 306 a 308 del Texto Refundido de la Ley de Puertos del Estado y la Marina Mercante de 5 de septiembre de 2001; o, en fin, el art. 46 de la Ley de Residuos y Suelos Contaminados de 28 de julio de 2011.

La misma comprobación es válida igualmente para las leyes de las Comunidades Autónomas. Baste al respecto con los siguientes botones de muestra: los arts. 75.2 y 76.2 de la Ley 22/2007, de 18 de diciembre, de Farmacia de Andalucía; el art. 57, en relación con los arts. $59 \mathrm{~m}$ ) y $60 \mathrm{~m}$ ) de la Ley 7/2011, de 23 de marzo, de Salud Pública de Extremadura; y los arts. 6.1 y 7 del Decreto-ley 11/2020, de 24 de julio, de régimen sancionador específico contra los incumplimientos de las disposiciones reguladoras de las medidas de prevención contra COVID-19. 
REALA. Nueva Época - N.o 16, octubre 2021 - ISSN: 1989-8975 - DOI: https://doi.org/10.24965/reala.i16.10947 - [Págs. 53-70]

La graduación ad hoc de las infracciones. Motivos para la discusión

Miguel Casino Rubio

Andaluza de Administración Pública, 85. Instituto Andaluz de Administraciones Públicas. https://doi.org/10.46735/ raap.n85.1007

Gómez Tomillo, M. y Sanz Rubiales, I. (2013). Derecho administrativo sancionador. Parte General (3. ${ }^{a}$ ed.). Thomson Reuters-Aranzadi.

Izquierdo Carrasco, M. (2001). La determinación de la sanción administrativa. Revista Justicia Administrativa, Extra-1, 207-258.

Nieto, A. (2012). Derecho Administrativo Sancionador (5. ${ }^{a}$ ed.). Tecnos.

Rebollo Puig, M. y Cano Campos, T. (2021). Es constitucional el art. 117.1 del Texto Refundido de la Ley de Aguas? [texto inédito].

Valencia Martín, G. (2000). Derecho administrativo sancionador y principio de legalidad. En El principio de legalidad. Actas de las V Jornadas de la asociación de Letrados del Tribunal Constitucional. CEPC/Tribunal Constitucional.

Valencia Martín, G. (2018). El derecho a la legalidad sancionadora en el ámbito administrativo. En M. Rodríguez-Piñero y Bravo Ferrer y M. E. Casa Baamonde (dirs.), Comentarios a la Constitución española (Tomo I). Wolters Kluwer. 